Volume 10, Nomor 1, Mei 2018, pp 1-16 Copyright (C) 2017 Jurnal Akuntansi Maranatha, Program Studi Akuntansi, Fakultas Ekonomi, Universitas Kristen Maranatha. ISSN 2085-8698 | e-ISSN 2598-4977. http://journal.maranatha.edu

\title{
Peranan Use-casemodeling Dalam Menilai Tingkat Efektivitas Siklus Pengeluaran (Studi Kasus CV Makmur Abadi)
}

\author{
Ivan Senjaya \\ Fakultas Ekonomi Program Studi Magister Manajemen \\ Universitas Katolik Parahyangan \\ (Jln. Merdeka No. 30, Bandung) \\ Ivansenjaya32@gmail.com
}

\begin{abstract}
The change of time, technology, and competition influence indirectly to company's environment. This makes company should to review the aspects that exist within the company, one of which is the effectiveness of the company cycle. One main function of accounting information system is processing the data into useful information for decision makers to make the cycle to be effective so that corporate goals can be achieved. Use-case modeling is one of the documentation tools in the accounting information system that can also generate information about the effectiveness of a cycle. This research used analytical descriptive method as research method with data collection techniques by interview, observation, and library research. Object of this case study of research is CV Makmur Abadi, a company in textile industry. After the research process is done, it can be concluded that the role of use-case modeling in assessing effectiveness is as a supporting role by providing guidance. Use-case can provide guidance on assessing the effectiveness of cycle especially by components in use-case such as use-case narratives and use-case dependencies diagrams. With these guidance, the process assessment of effectiveness becomes more systematic to present accurate and useful information.
\end{abstract}

Keywords: Use-case Modeling, Assessment of Effectiveness Level, \& Expenditure Cycle.

\section{Pendahuluan}

Sektor industri di Indonesia terdiri dari beberapa subsektor, salah satunya adalah industri tekstil. Industri tekstil di Indonesia merupakan industri yang memiliki prospek yang cukup menjanjikan. Industri tekstil merupakan industri dengan jumlah karyawan terbanyak kedua (ketiga pada tahun 2012) dari seluruh sektor industri sedang besar di Indonesia periode tahun 2010 sampai dengan 2015. Industri tekstil juga memiliki perusahaan sekitar 9\% sampai $10 \%$ dari total kurang lebih 24.000 industri pada sektor sedang besar industri di Indonesia untuk periode tahun 2010 sampai dengan 2015. Akan tetapi secara index produksi, industri tekstil mengalami penurunan selama periode tahun 2010 
sampai dengan 2015. Tabel 1 menunjukkan statistik jumlah perusahaan dan indeks produksi rata-rata industri tekstil ukuran sedang dan besar pada tahun 2010 hingga 2015.

\section{Tabel 1}

Statistik Jumlah Perusahaan dan Indeks Produksi Rata-rata Industri Tekstil Sedang dan Besar

\begin{tabular}{|l|c|c|c|c|c|c|}
\hline \multicolumn{1}{|c}{} & $\mathbf{2 0 1 0}$ & $\mathbf{2 0 1 1}$ & $\mathbf{2 0 1 2}$ & $\mathbf{2 0 1 3}$ & $\mathbf{2 0 1 4}$ & $\mathbf{2 0 1 5}$ \\
\hline Jumlah Perusahaan (unit) & 2,333 & 2,251 & 2,246 & 2,287 & 2,555 & 2,612 \\
\hline $\begin{array}{l}\text { Index Produksi rata-rata } \\
(2010=100.0)\end{array}$ & 100.00 & 92.29 & 84.64 & 77.32 & 73.09 & 71.63 \\
\hline
\end{tabular}

\section{Sumber: Badan Pusat Statistik Indonesia 2017 (www.bps.go.id)}

CV Makmur Abadi adalah salah satu perusahaan pada subsektor industri tekstil. CV Makmur Abadi merupakan perusahaan yang menghasilkan kain corak untuk dijual ke perusahaan pengolah kain atau garmen. Penurunan indeks produksi dan meningkatnya jumlah perusahaan pada industri tekstil menunjukkan adanya peningkatan persaingan dalam industri tersebut. CV Makmur Abadi harus membuat siklus pengeluaran menjadi efektif agar dapat bersaing dengan perusahaan lain.

Sistem informasi akuntansi, yang merupakan salah satu cabang dari ilmu akuntansi, merupakan sebuah ilmu yang mempelajari cara mengolah data menjadi informasi yang berguna bagi pembuat keputusan dalam perusahaan. Aktivitas utama yang ada di dalam perusahaan terbagi menjadi beberapa siklus, salah satunya adalah siklus pengeluaran. Sistem informasi merupakan aktivitas pendukung dalam menambah nilai dalam perusahaan sehingga aktivitas utama akan berjalan dengan efektif.

Use-case merupakan salah satu alat dokumentasi pada sistem informasi akuntansi. Penggunaan use-case dalam menggambar sebuah siklus dapat bermanfaat karena dapat mengetahui secara lengkap kebutuhan pengguna (user) dan stakeholder terkait. Dari penggambaran use-case akan menunjukkan aktivitasaktivitas yang ada di dalam sebuah siklus dan informasi lainnya terkait efektivitas siklus. Informasi yang dihasilkan dari penggunaan use-case bermanfaat bagi pihak yang berkepentingan dalam membuat keputusan.

Efektivitas adalah suatu keadaan yang menekankan akan pencapaian hasil atau tujuan yang telah ditetapkan. Informasi yang didapatkan dari penggunaan use-case dapat diolah untuk menilai tingkat efektivitas sebuah siklus. Informasi tingkat efektivitas dari suatu siklus kemudian dipertimbangkan oleh manajer. Manajer membuat keputusan mengenai langkah yang akan dilakukan. Manajer akan memilih memperbaharui atau memperbaiki siklus tersebut apabila siklus tersebut kurang efektif.

Pembaharuan atau perbaikan pada siklus ini akan membuat siklus menjadi efektif sehingga tujuan siklus akan tercapai. Tercapainya tujuan siklus juga akan mendukung pencapaian tujuan perusahaan

\section{Kerangka Teoritis}

\section{Sistem Informasi Akuntansi}

Accounting information system adalah sistem yang mengumpulkan, mencatat, dan mengolah data mengenai transaksi financial dan nonfinancial menjadi informasi yang akan digunakan untuk membuat keputusan bagi perusahaan (Romney dan Steinbart, 2009 dan Hall, 2008).

\section{Peran Sistem Informasi Akuntansi}

Sebagai aktivitas pendukung, sistem informasi akuntansi dapat memberi informasi yang akurat dan tepat sehingga dapat menghasilkan tambahan nilai (value). Hal ini dapat membuat sistem informasi akuntansi menghasilkan berbagai macam 
keuntungan, yaitu (Romney dan Steinbart, 2009):

1. Meningkatkan kualitas dan mengurangi biaya produksi dari produk dan jasa.

2. Meningkatkan efisiensi kegiatan operasi.

3. Membagi pengetahuan.

4. Meningkatkan efektivitas dan efisiensi dari supply chain.

5. Meningkatkan internal control perusahaan.

6. Meningkatkan proses membuat keputusan.

\section{Use-case}

Dalam mengembangkan suatu sistem, kadang-kadang timbul berbagai macam kendala ketika proses tersebut sedang berjalan ataupun ketika sistem tersebut selesai dikembangkan. Kebutuhan akan suatu sistem seharusnya disebutkan secara terperinci dan jelas sebelum proses pengembangan itu dilakukan. Kebutuhan ini harus didiskusikan bersama pengguna (user) agar mendapatkan hasil yang tepat sesuai dengan yang diinginkan oleh user, hal ini mencakup permasalahan kebutuhan, waktu, dan juga biaya. User-centered development adalah konsep untuk mengatasi permasalahan di atas, yaitu sebuah konsep pengembangan sistem dimana kebutuhan stakeholder dan alasan pengembangan sistem dianalisis dan dimengerti terlebih dahulu. Salah satu cara pendekatan user-centered development yang dapat digunakan adalah use-casemodeling. Penggunaan use-casemodeling ini lebih diunggulkan dibandingkan dengan pendekatan lainnya sebab use-casemodeling lebih mudah dipahami oleh orang awam (Bentley dan Whitten, 2007).

Use-casemodeling adalah proses yang menjelaskan kegiatan bisnis mengenai siapa yang menjalankan bisnis dan bagaimana tanggapan dari sistem atas kegiatan bisnis tersebut dalam bentuk gambar atau model. Use-case modeling dapat memberi informasi mengenai kebutuhan yang diperlukan pada suatu sistem berdasarkan sudut pandang user dan stakeholder (Bentley dan Whitten, 2007).

\section{Komponen use-case modeling}

Terdapat dua komponen utama dalam use-case modeling yaitu (Bentley dan Whitten, 2007):

\section{Use-case diagram}

Use-case diagram adalah sebuah bagan yang menggambarkan hubungan antara sistem dengan user, yaitu pihak yang akan menggunakan sistem dan interaksi yang timbul.

Terdapat empat alat pada use-case diagram yaitu:

a. Use cases

Use case adalah suatu penggambaran dari tujuan yang hendak dicapai dengan sebuah tugas. Penggambarannya berbentuk elips dengan nama tugas di dalamnya. Penggunaan use-case dapat memberi informasi mengenai permasalahan dalam bisnis dan fungsi dari pengembangan sistem yang diusulkan (Bentley dan Whitten, 2007).

b. Actors

Actor adalah pemicu atau pihak yang memulai menjalankan tugas yang ada di dalam use-case. Yang termasuk ke dalam actor adalah manusia, benda mati, maupun suatu konsep (contoh: waktu). Actor yang merupakan pemicu utama dari use-case, terbagi menjadi empat jenis (Bentley dan Whitten, 2007):

i. Primary business actor

Primary business actor adalah stakeholder yang mendapatkan keuntungan atau value dari pelaksanaan use-case. Actor ini bisa berperan sebagai pelaksana 
dari use-case maupun hanya sebagai penerima keuntungan saja.

ii. Primary system actor

Primary system actor adalah stakeholder yang menjadi pemicu utama dari pelaksanaan use-case. Actor ini menjalankan tugas sebagai pelaksana yang berhubungan dengan primary business actor. Kadangkadang primary business actor dan primary system actor bisa dilakukan oleh orang yang sama, contoh: orang yang memesan tiket pesawat terbang melalui website.

iii. External server actor

External server actor adalah stakeholder yang menanggapi semua permohonan yang timbul dari use-case.

iv. External receiver actor

External receiver actor adalah stakeholder selain dari primary business actor yang mendapat output dari use-case.

c. Relationship

Relationship menunjukkan hubungan antara actor dengan use-case maupun use-case dengan use-case lainnya. Relationship ini terbagi menjadi beberapa macam sesuai dengan hubungan yang timbul, yaitu(Bentley dan Whitten, 2007):

a) Association

\section{Association relationship} merupakan sebuah garis yang menunjukkan hubungan antara actor dengan use-case maupun use-case dengan usecase lainnya. Terbagi menjadi dua jenis, yaitu: garis tanpa tanda panah dan garis dengan tanda panah. Garis tanpa tanda panah menunjukkan adanya interaksi antara dua komponen tersebut. Garis dengan tanda panah menunjukkan salah satu actor atau use-case yang mempengaruhi actor atau usecase lainnya.

b) Extends

Extends relationship adalah hubungan antara use-case dengan use-case yang lainnya dimana akan memperluas sebuah use-case. Perluasan ini dilakukan sebab use-case yang diperluas cenderung berisi sebuah tugas yang cukup sulit dimengerti dengan menggunakan sebuah use-case sehingga akan memunculkan extensionuse-case.

Penggunaan extensionusecase tidak menambah jenis tugas yang harus dibuat, sebab extensionuse-case memiliki fungsi dasar yang sama dengan use-case semula yang diperluas tersebut. Perluasan juga akan mempermudah memahami use-case yang kompleks tersebut.

c) Includes

Includes relationship adalah hubungan antara use-case dengan use-case yang lain dimana hubungan ini timbul oleh dua atau lebih use-case yang memiliki fungsi yang serupa sehingga membentuk abstractuse-case. Hubungan use-case dengan abstractusecase itulah yang disebut includes relationship. Penggunaan relationship ini dapat menghilangkan duplikasi pekerjaan yang sama dari beberapa use-case sehingga ditampung dalam 
sebuah use-case, yaitu di dalam abstractuse-case.

d) Depends On

Depends on relationship adalah hubungan antara usecase dengan use-case yang lain dimana sebuah use-case tidak dapat dijalankan tanpa ada dan dijalankannya usecase lain terlebih dahulu. Relationship ini menunjukkan use-case yang menjadi kunci dalam sebuah sistem apabila use-case itu menjadi sumber utama dari dependency.

e) Inheritance

Inheritance relationship adalah sebuah hubungan antar actor dengan actor lain dimana hubungan ini akan membentuk abstract actor. Abstract actor ini muncul dari adanya hubungan dua actor terhadap satu use-case yang sama dimana abstract actor ini menjadi actor utama ataupun yang sebenarnya akan mempengaruhi atau menjalankan use-case tersebut.

d. System boundaries

System boundaries adalah sebuah kotak yang terdiri dari dua atau lebih use-case yang memiliki hubungan yang sama dalam sebuah sistem atau subsistem. System boundaries, yang menjadi sekat pembatas antara sistem atau subsistem yang ada, diberi nama sesuai dengan sistem atau subsistem tersebut (Dennis et al., 2005).

Gambar 1 menunjukkan contoh simbol yang umumnya dipakai dalam use-case diagram.

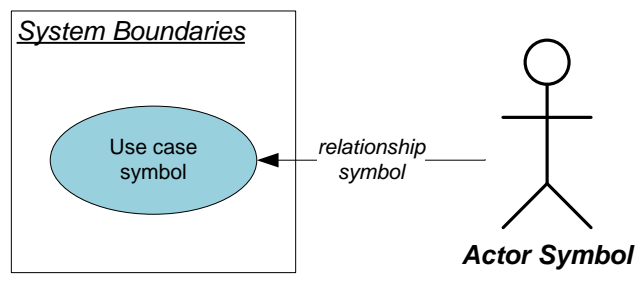

Gambar 1

Contoh simbol dalam usecasediagram

Sumber: Bentley dan Whitten, 2007 dan Dennis et al., 2005 (diadaptasi)

\section{Use-case narrative}

Use-case narrative adalah penjelasan tertulis tentang suatu kegiatan bisnis mengenai interaksi atau hubungan antara user dengan sistem.

Use-case narrative berisi berbagai macam komponen yang terbagi menjadi dua komponen utama yaitu (Bentley dan Whitten, 2007; Dennis et al., 2005; George dan Batra, 2004):

a. Primary

- Use case ID: nomor use case.

- Use case Name: nama use case.

- Use case Type: tipe use case.

- Primary Actor: actor utama yang mempengaruhi atau menjalankan use case.

- Stakeholders and interest: pihak-pihak lain yang tertarik pada aktivitas use case beserta tindakannya.

- Trigger: yang menjadi pemicu timbulnya use-case, bisa use case, dokumen, stakeholder, atau benda mati (waktu).

- Description: penjelasan singkat mengenai aktivitas use case dan tujuannya

- Course of event: langkahlangkah kegiatan yang dilakukan dalam use case secara terperinci. 
- Alternate course: langkahlangkah alternatif yang timbul untuk langkah utama bila ada kejadian-kejadian di luar langkah utama muncul.

\section{b. Expanded}

- Priority: prioritas dari use case tersebut, use-case ranking and priority matrix dapat membantu mengisi priority.

- Precondition: syarat utama sebelum use-case dapat dijalankan.

- Postcondition: hasil (output) dari hasil aktivitas use case.

- Businessrules: peraturan yang berlaku berkaitan dengan use case.

- Assumption: asumsi yang ada dalam use case.

- Otheractor: actors lain yang muncul dalam use case.

\section{Fungsi Penilaian Use-case}

Setelah use-case modeling selesai dibuat, use-case yang ada di dalamnya dapat dinilai untuk mengetahui use case yang menjadi prioritas utama dan use case yang dapat ditunda terlebih dahulu. Terdapat dua cara untuk menilai, yaitu:

\section{a. Ranking and Evaluating Use-cases}

Alat yang digunakan untuk membandingkan dan evaluasi usecase adalah dengan menggunakan use-case ranking and priority matrix, yaitu tabel yang menunjukkan tingkat prioritas dari use-case yang ada. Row atau record berisi semua use-case yang ada. Column berisi ranking criteria, total score, priority, dan build cycle. Ranking criteria berisi nilai masing-masing kriteria dari 1 sampai 5. Ranking criteria untuk menilai setiap use case terdiri dari enam kriteria, yaitu use-case tersebut akan:
1. Memberi pengaruh pada rancangan arsitektur.
2. Mudah pelaksanaannya tetapi memiliki pengaruh penting.

3. Termasuk fungsi yang beresiko, kompleks, dan mempergunakan waktu yang banyak.

4. Melibatkan penelitian, resiko, atau penggunaan teknologi baru.

5. Termasuk fungsi bisnis utama.

6. Berpengaruh dalam meningkatkan laba atau mengurangi biaya.

Total score adalah total nilai yang didapat dari ranking criteria. Priority adalah tingkat prioritas dari suatu use-case yang dapat dilihat dari total score, biasanya berisi high, medium, atau low. Build cycle adalah angka yang menentukan pembuatan usecase tersebut dalam bisnis, angka 1 menunjukkan pembentukan use-case yang pertama (Bentley dan Whitten, 2007).

b. Identifying Use-cases Dependencies Alat yang dapat digunakan untuk mengidentifikasi use-case dependencies adalah use-case dependency diagram, yaitu suatu diagram yang menunjukkan hubungan ketergantungan antara usecase dengan use-case yang lain. Penggunaan diagram ini akan memberi beberapa keuntungan, yaitu:

1. Menggambarkan sistem dan kedudukan use-case sehingga memberi pengertian akan fungsi sistem secara keseluruhan.

2. Membantu menemukan use-case yang seharusnya ada.

3. Menunjukkan use-case yang menjadi prioritas utama, dilihat dari ketergantungan yang paling tinggi (Bentley dan Whitten, 2007).

\section{Siklus Pengeluaran}

Siklus pengeluaran adalah sekumpulan aktivitas dan informasi yang diperlukan untuk proses pengolahan berhubungan 
dengan pembelian dan pembayaran barang dan jasa. Tujuan utama dari siklus pengeluaran adalah untuk mengurangi biaya untuk mendapatkan barang atau jasa dan menjaga hubungan dengan pihak yang berkepentingan agar siklus berjalan dengan baik (Romney dan Steinbart, 2009).

\section{Fungsi Sistem Informasi Akuntansi dalam Siklus Pengeluaran}

Salah satu fungsi dari sistem informasi akuntansi adalah menyediakan pengendalian yang tepat agar dapat mencapai tujuan utama, yaitu (Romney dan Steinbart, 2009):

1. Semua transaksi telah diotorisasi.

2. Semua transaksi yang telah dicatat sah.

3. Semua transaksi yang sah dan telah diotorisasi dicatat.

4. Semua transaksi dicatat dengan akurat.

5. Melindungi dan menjaga aset perusahaan.

6. Aktivitas bisnis dilaksanakan secara efektif dan efisien.

Fungsi lain dari sistem informasi akuntansi adalah menyediakan informasi yang berguna. Informasi yang dihasilkan sistem informasi akuntansi dalam siklus pengeluaran akan berguna untuk melaksanakan aktivitas (Romney dan Steinbart, 2009):

a. Menentukan waktu dan jumlah persediaan yang harus dipesan.

b. Menentukan pemasok yang tepat.

c. Memeriksa supplier invoice dengan akurat.

d. Menentukan pengambilan diskon pembelian.

e. Memantau arus kas yang dibutuhkan untuk membayar obligasi yang belum dibayar.

\section{Metode Penelitian}

Metode penelitian yang digunakan dalam penelitian ini adalah metode deskriptif analitis. Data yang telah dikumpulkan dicatat dan dianalisis berdasarkan teoriteori yang berkaitan dengan masalah dalam penelitian. Hasil penelitian digunakan sebagai dasar untuk membuat kesimpulan dan memberi saran.

Variabel penelitian yang digunakan dalam penelitian terdiri dari tiga, yaitu independent variable yang dalam penelitian ini adalah penerapan use-case, mediating variable yang dalam penelitian ini adalah informasi, dan dependent variable yang dalam penelitian ini adalah proses penilaian tingkat efektivitas siklus pengeluaran. Gambar 2 menunjukkan hubungan variabel-variabel yang ada dalam penelitian.

Untuk mendapat data yang akurat, penelitian ini menggunakan beberapa teknik pengumpulan data, yaitu: wawancara yang terbagi menjadi dua jenis, yaitu terstruktur dan tidak terstruktur; observasi untuk membuktikan data wawancara; dan penelitian kepustakaan untuk memiliki landasan teori.

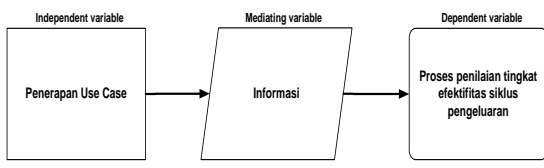

Gambar 2

Variabel Penelitian

Sumber bentuk lambang variabel:

Sekaran dan Bougie, 2010 


\section{Hasil Penelitian dan Pembahasan}

CV Makmur Abadi adalah perusahaan tekstil yang mengolah benang menjadi kain corak yang objek penelitian ini. Usecase modeling akan digunakan untuk menilai efektivitas siklus pengeluaran $\mathrm{CV}$ Makmur abadi. Sebelum menilai tingkat efektivitas, langkah yang harus dilakukan adalah membuat use-case modeling untuk menggambarkan siklus pengeluaran $\mathrm{CV}$ Makmur Abadi sesuai dengan langkahlangkah berikut ini, yaitu (Bentley dan Whitten, 2007):

1. Identify business actors.

2. Identify business requirements usecases.

3. Construct use-case model diagram.

4. Document business requirement usecase narratives.

Langkah-langkah tersebut dilakukan untuk menggambarkan siklus pengeluaran di CV Makmur Abadi hingga terbentuk use-case modeling beserta komponen-komponen di dalamnya. Lampiran 1. menunjukkan secara terperinci langkah-langkah pembuatan use-case modeling dalam penelitian pada siklus pengeluaran $\mathrm{CV}$ Makmur Abadi.

Setelah proses pembuatan use-case modeling akan siklus pengeluaran selesai dibuat, use-case modeling tersebut akan dinilai lebih lanjut menggunakan usecase ranking and priority matrix dan usecase dependencies untuk menghasilkan informasi tambahan. Gambar 3. menunjukkan diagram use-case dependencies siklus pengeluaran $\mathrm{CV}$ Makmur Abadi. Tabel 2 menunjukkan tabel use-case ranking and priority matrix siklus pengeluaran di CV Makmur Abadi.

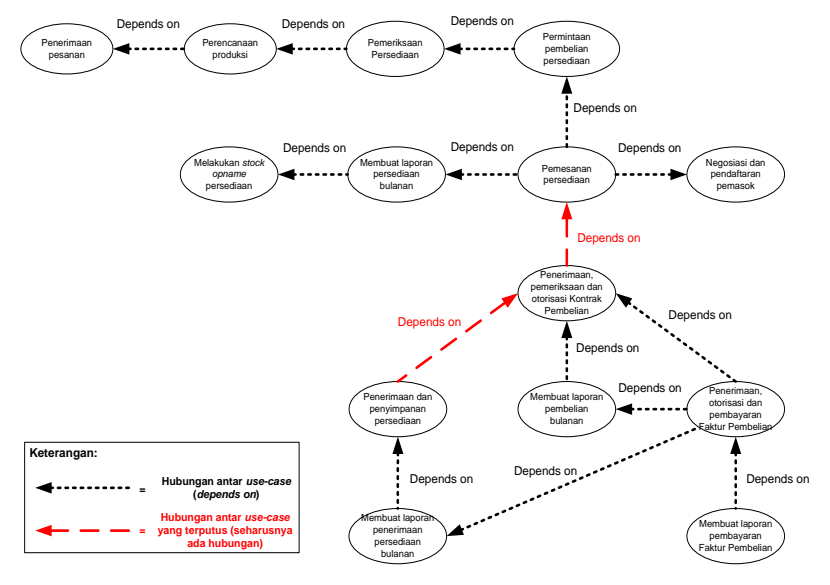

Gambar 3

Use-case Dependencies Diagram Siklus Pengeluaran CV Makmur Abadi Sumber: CV Makmur Abadi

Tabel 2

Use-case Ranking and Priority Matrix Siklus Pengeluaran CV Makmur Abadi

\begin{tabular}{|c|c|c|c|c|c|c|c|c|c|}
\hline \multirow{3}{*}{ No } & \multirow{3}{*}{ Use case Name } & \multirow{2}{*}{\multicolumn{6}{|c|}{$\begin{array}{c}\text { Ranking Criteria } \\
\text { (1 to 5) } \\
\end{array}$}} & \multirow{3}{*}{$\begin{array}{l}\text { Total } \\
\text { Score }\end{array}$} & \multirow{3}{*}{ Priority } \\
\hline & & & & & & & & & \\
\hline & & 1 & 2 & 3 & 4 & 5 & 6 & & \\
\hline 1 & Penerimaan pesanan & 5 & 5 & 5 & 4 & 5 & 5 & 29 & High \\
\hline 2 & Perencanaan produksi & 5 & 5 & 5 & 4 & 5 & 5 & 29 & High \\
\hline 3 & Pemeriksaan persediaan & 4 & 3 & 3 & 3 & 4 & 2 & 19 & Medium \\
\hline 4 & Permintaan pembelian persediaan & 3 & 4 & 4 & 2 & 4 & 4 & 21 & High \\
\hline 5 & Melakukan stock opname persediaan & 3 & 3 & 5 & 2 & 4 & 3 & 20 & Medium \\
\hline 6 & Membuat laporan persediaan bulanan & 4 & 5 & 3 & 3 & 4 & 2 & 21 & $\mathrm{High}$ \\
\hline 7 & Pemesanan persediaan & 5 & 5 & 5 & 3 & 5 & 5 & 28 & $\mathrm{High}$ \\
\hline 8 & Melihat daftar pemasok & 4 & 5 & 4 & 3 & 4 & 4 & 24 & High \\
\hline 9 & Menerima dan melihat dokumen pendukung & 4 & 5 & 4 & 3 & 4 & 3 & 23 & $\mathrm{High}$ \\
\hline 10 & Negosiasi dan pendaftaran pemasok & 4 & 4 & 5 & 1 & 3 & 3 & 20 & Medium \\
\hline 11 & Mencari rekanan pemasok & 3 & 3 & 5 & 1 & 3 & 3 & 18 & Medium \\
\hline 12 & $\begin{array}{l}\text { Penerimaan, pemeriksaan dan otorisasi } \\
\text { Kontrak Pembelian }\end{array}$ & 5 & 5 & 5 & 3 & 5 & 5 & 28 & High \\
\hline 13 & Membuat laporan pembelian bulanan & 4 & 4 & 3 & 3 & 4 & 2 & 20 & Medium \\
\hline 14 & Penerimaan dan penyimpanan persediaan & 4 & 5 & 4 & 3 & 5 & 3 & 24 & High \\
\hline 15 & Membuat laporan penerimaan persediaan & 4 & 4 & 3 & 3 & 4 & 2 & 20 & Medium \\
\hline 16 & $\begin{array}{l}\text { Penerimaan, otorisasi, dan pembayaran } \\
\text { Faktur Pembelian }\end{array}$ & 4 & 5 & 5 & 3 & 5 & 5 & 27 & High \\
\hline 17 & $\begin{array}{l}\text { Membuat laporan pembayaran Faktur } \\
\text { Pembelian }\end{array}$ & 4 & 4 & 3 & 3 & 4 & 2 & 20 & Medium \\
\hline
\end{tabular}

Sumber: CV Makmur Abadi

Informasi yang dihasilkan dari pembuatan use-case modeling antara lain:

- Adanya pembatasan yang jelas subsistem yang ada di suatu siklus perusahaan melalui system boundaries yang berguna untuk menilai kinerja 
sesuai dengan subsistem yang ada di perusahaan dan mempermudah pembaharuan sesuai dengan subsistem yang jelas.

- Penjelasan yang lengkap dalam usecase narrative mencakup pembahasan stakeholders and interest dan post condition dapat membantu untuk mempermudah mengetahui faktorfaktor penting dalam penilaian efektivitas CV Makmur Abadi.

- Masalah yang ada di siklus pengeluaran perusahaan, yaitu

1. Tidak ada dokumen Purchase Order dan proses otorisasi.

2. Tidak ada informasi dari bagian pembelian ke bagian gudang atas pembelian yang dilakukan.

3. Beberapa persediaan tidak memiliki kartu stok.

4. Kepala Bagian Gudang merangkap fungsi authorization dan recording dalam penerimaan barang.

5. Rangkap fungsi recording dan custody pada jabatan Kepala Bagian Keuangan. Akan tetapi Kepala Bagian Keuangan dipegang oleh orang kepercayaan perusahaan.

- Use case yang mendapat prioritas tinggi perlu dikelola dan dikendalikan oleh perusahaan dengan baik. Berdasarkan prioritasnya, terdapat sepuluh use case yang mendapat pertingkat High (scoreuse case lebih tinggi dari 20 angka), yaitu: Penerimaan pesanan, Perencanaan produksi, Pemesanan persediaan, Penerimaan, pemeriksaan dan otorisasi Kontrak Pembelian, Penerimaan, otorisasi, dan pembayaran Faktur Pembelian, Melihat daftar pemasok, Penerimaan dan penyimpanan persediaan, Menerima dan melihat dokumen pendukung, Permintaan pembelian persediaan, dan Membuat laporan persediaan bulanan. Lebih lanjut lagi, terdapat dua use case yang mendapat score tertinggi (29 angka) adalah Penerimaan Pesanan dan Perencanaan Produksi.

- Berdasarkan Use case dependencies diagram, didapatkan informasi berikut:

1. Use case Penerimaan Pesanan menjadi sumber utama use case lainnya sehingga perusahaan harus menjaga agar use case tersebut dapat berjalan secara berkelanjutan.

2. Tidak adanya hubungan antara use case Pemesanan Persediaan dengan use case Penerimaan, Pemeriksaan dan Otorisasi Kontrak Pembelian dan use case Penerimaan, Pemeriksaan dengan Otorisasi Kontrak Pembelian dengan use case Penerimaan dan Penyimpanan Persediaan. Hal ini menunjukkan adanya arus informasi yang tidak berjalan dengan baik pada siklus pengeluaran CV Makmur Abadi.

Tujuan utama dari siklus pengeluaran CV Makmur Abadi melalui hasil wawancara adalah agar siklus pengeluaran dapat memenuhi persediaan yang dibutuhkan untuk kegiatan produksi perusahaan dengan kualitas dan waktu yang tepat. Berdasarkan kajian literatur, diketahui juga faktor-faktor yang diperlukan dalam menilai tingkat efektivitas siklus pengeluaran. Dan secara khusus untuk penggambaran use-case modeling pada penelitian ini, faktorfaktor yang penting dalam penilaian efektivitas siklus pengeluaran $\mathrm{CV}$ Makmur Abadi adalah:

1. Hasil (output) atau tujuan siklus pengeluaran yang ditetapkan dan hasil yang sebenarnya.

2. Hubungan perusahaan dengan pihak yang berkepentingan dan hubungan use case dengan stakeholders. 
Secara khusus komponen yang berperan dalam menilai tingkat efektivitas siklus pengeluaran adalah:

a. Use-case dependencies diagram yang menunjukkan hubungan ketergantungan antar use-case dalam siklus pengeluaran. Jika ada hubungan yang terputus menunjukkan siklus tersebut belum berjalan secara efektif dalam mencapai tujuan perusahaan.

b. Use-case narrative yaitu dengan menggunakan komponen post condition. Post condition bisa memberi ketentuan hasil (output) yang diharapkan atau yang telah ditetapkan oleh perusahaan untuk setiap use case yang ada. Komponen ini akan dibandingkan dengan hasil (output) yang sebenarnya. Hasil penelitian pada siklus pengeluaran CV Makmur Abadi ditemukan bahwa Use case Melakukan stock opname persediaan, Penerimaan, pemeriksaan dan otorisasi Kontrak Pembelian dan Penerimaan, otorisasi, dan pembayaran Faktur Pembelian memiliki hasil sebenarnya sesuai dengan post condition akan tetapi dalam pelaksanaannya untuk mencapai hasil tersebut sering kali membutuhkan waktu dan tenaga lebih dari yang seharusnya.

c. Use-case narrative yaitu dengan menggunakan komponen stakeholders and interest. Stakeholders and interest dapat memberi informasi mengenai pihak-pihak intern dan ekstern yang menjadi perhatian CV Makmur Abadi agar siklus pengeluaran tetap berjalan dengan baik. Hasil penelitian pada siklus pengeluaran CV Makmur Abadi ditemukan bahwa Use case Perencanaan produksi, Pemesanan persediaan, dan Penerimaan, pemeriksaan dan otorisasi Kontrak Pembelian belum terbentuk hubungan yang baik dengan para stakeholder dalam use-case itu.

\section{Simpulan dan Saran}

\section{Simpulan}

Peranan use-case dalam menilai tingkat efektivitas siklus pengeluaran adalah sebagai peran pembantu dalam melakukan penilaian tersebut. Selain memberi gambaran secara visual, use-case juga dapat memberi arahan mengenai penilaian efektivitas. Arahan ini didapatkan dari komponen-komponen yang ada di dalam use-case seperti use-case narrative dan usecase dependencies diagram. Dengan adanya arahan tersebut, proses penilaian efektivitas menjadi lebih sistematis dan akurat sehingga dapat menyajikan informasi yang berguna bagi para pengambil keputusan. Jadi para pengambil keputusan bisa melakukan perbaikan atau pembaharuan siklus pada area atau sektor dengan tepat sehingga siklus menjadi efektif dan tujuan siklus tercapai.

\section{Saran}

\section{Untuk Perusahaan}

1. Penambahan peraturan pada use case Penerimaan Pesanan yaitu hanya menerima pesanan sesuai dengan jenis benang yang sudah memiliki rekanan pemasoknya untuk mengatasi masalah belum tersedianya rekanan pemasok yang menyediakan persediaan benang tertentu.

2. Menggunakan dokumen Purchase Order untuk mengatasi terputusnya hubungan use case dalam siklus. Purchase Order dapat memberikan manfaat sebagai otorisasi dan sebagai media notifikasi untuk bagian gudang dan penerimaan yang diberikan dalam bentuk blind copy.

3. Evaluasi kinerja Kepala Bagian Gudang dan Staf Gudang untuk melengkapi semua jenis persediaan yang belum memiliki kartu stok. Selain itu, juga pembaharuan peraturan mengenai pembuatan kartu stok yang dilakukan oleh Staf 
Gudang Benang diubah menjadi dibuat oleh Kepala Bagian Gudang.

4. Pemisahan fungsi authorization dan recording pada Kepala Bagian Gudang untuk membagi tanggung jawab dan fungsi dalam menyimpan dan menjaga persediaan.

5. Meskipun Kepala Bagian Keuangan yang merangkap fungsi recording dan custody dipegang oleh orang kepercayaan, perusahaan disarankan untuk mulai memisahkan rangkap jabatan tersebut. Hal ini untuk mengantisipasi kalau karyawan kepercayaan tersebut berhalangan hadir atau tidak dapat bekerja kembali.

\section{Untuk Peneliti Berikutnya}

Penggunaan use-case modeling yang masih sangat jarang dalam penggambaran suatu siklus membuat penelitian ini menjadi salah satu dari sedikit penelitan yang meneliti peran use-case modeling dalam menilai tingkat efektivitas siklus pengeluaran. Peneliti memberi saran untuk penelitian berikutnya, agar melakukan penelitan pada siklus pengeluaran pada studi kasus perusahaan lainnya untuk memberikan gambaran yang lebih umum akan peran use-case modeling dalam menilai tingkat efektivitas siklus pengeluaran. Peneliti juga memberi saran, agar melakukan penelitian pada siklus-siklus lainnya untuk memberikan gambaran yang lebih umum akan peran use-case modeling dalam menilai tingkat efektivitas siklussiklus tersebut.

\section{Ucapan Terimakasih}

Bapak Michael Iskandar, Drs., M.T. yang telah meluangkan waktu, tenaga, dan pikiran untuk memberikan masukan dan pengetahuan mengenai penyusunan jurnal maupun di luar pembahasan jurnal ini.

\section{Daftar Pustaka}

Badan Pusat Statistik Indonesia. (2017).

Statistik Indonesia 2017.

https://www.bps.go.id/linkTabel

Statis/view/id/1057 dan

https://www.bps.go.id/linkTable

Dinamis/view/id/896 diakses

tanggal 8November 2017 pukul

18.58 WIB.

Bentley, Lonnie D. dan Jeffrey L.

Whitten. (2007). Edisi 7. System

Analysis and Design for The

Global Enterprise. New York:

McGraw-Hill International

Edition.

Dennis, Alan, Barbara Haley Wixom, David Tegarden. (2005). Edisi 2.

System Analysis and Design

With UML Version 2.0: An

Object-Oriented Approach. New

Jersey: Wiley International.

George, Joey F. dan Dinesh Batra. (2004). Object-Oriented System

Analysis and Design. New

Jersey : Prentice Hall

International.

Gelinas, Ulirc J. dan Richard B. Dull. (2008). Edisi 7. Accounting Information System. Mason: Thomson South-Western.

Hall, James. (2008). Edisi 7. Accounting information system. Mason: Thomson South-Western.

Romney, Marshall B. dan Paul John Steinbart. (2009). Edisi 11.

Accounting Information System.

New Jersey: Prentice-Hall International, Inc.

Sekaran, Uma dan Roger Bougie. (2010). Edisi 5. Research Metods For Business: A Skill Building Approach. New Jersey: John Wiley \& Sons Ltd.

Shelly, Garry B., Thomas J. Cashman, dan Harry J. Rosenblatt. (1998). Edisi 3. System Analysis and Design. Boston: Cashman International Series. 
Wulandari, Dinda dan Roberto Purba

Bisnis Indonesia. (2012, 02 April

| 17:14 WIB). "UKM GARMEN

keluhkan harga bahan baku -

Bisnis.com."

http://www.bisnis.com/articles/u

km-garmen-keluhkan-harga-

bahan-baku diakses tanggal 21

September 2012 pukul 21:02

WIB

\section{Lampiran}

Terdapat beberapa langkah untuk menggambar menggunakan use-case modeling dengan benar. Bentley dan Whitten menyebutkan empat langkah dalam melakukan use-case modeling. Berikut adalah langkah dan contoh penerapan penggambaran use-casemodeling pada siklus pengeluaran CV Makmur Abadi:

\section{Menentukan business actors}

Tahap pertama membuat use-case modeling adalah menentukan actor yang ada di dalam siklus. Penentuan actors dapat membantu proses penggambaran berikutnya dan juga mempermudah penentuan system boundaries dari sistem. Tabel 1 menunjukkan actor yang ada dalam siklus pengeluaran pada CV Makmur Abadi.

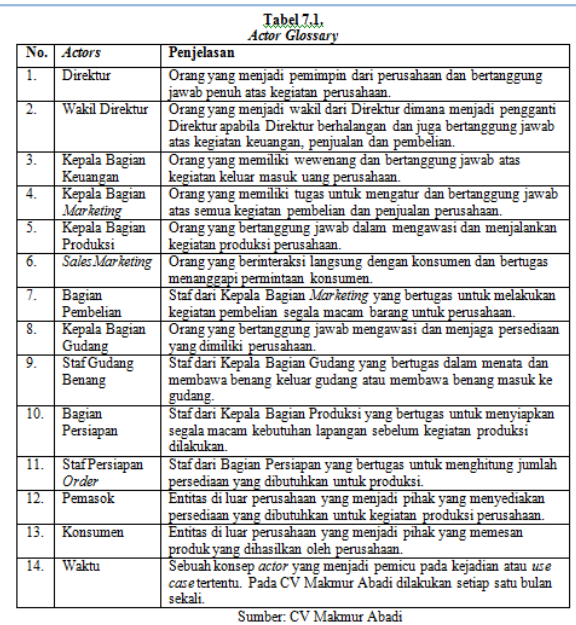

2. Menentukan use case yang dibutuhkan untuk menjalankan bisnis.

Tahap kedua membuat use-case modeling adalah menentukan seluruh use case yang terdapat dalam siklus pengeluaran. Penentuan use-case yang ada di siklus pengeluaran didapat setelah melakukan penelitian di $\mathrm{CV}$ Makmur Abadi. Use-case yang diidentifikasi adalah jenis overview use-case. Tabel 7.2. menunjukkan use case yang ada dalam siklus pengeluaran beserta penjelasannya pada CV Makmur Abadi. Tabel usecase glossary juga berisi daftar actor yang terlibat untuk setiap use-case.

\section{Membuat use-casemodel diagram.}

Tahap ketiga melakukan use-case modeling adalah membuat use-case model diagram. Use-case model diagram dapat menunjukkan actors, relationships dan system boundaries secara visual dengan jelas. System boundaries yang ada dalam siklus pengeluaran terdiri dari subsistem persediaan, pemesanan barang, pendaftaran pemasok, penerimaan barang dan pembayaran. Subsistem penjualan dan produksi tidak termasuk dalam siklus pengeluaran tetapi disertakan dalam pembahasan karena subsistem tersebut terkait dengan siklus pengeluaran secara tidak langsung. Gambar 7.1. menunjukkan use-case model diagram siklus pengeluaran $\mathrm{CV}$ Makmur Abadi. Dalam gambar ini actor Pemasok digambar dua kali. Actor Pemasok tersebut merupakan satu kesatuan Pemasok seperti yang dijelaskan dalam di Tabel 7.1., bukan dua Pemasok yang berbeda. Hal ini dilakukan untuk mempermudah penggambaran relationshipactor dengan use case. 
4. Membuat use-case narrative yang dibutuhkan untuk menjalankan bisnis.

Komponen use case type, priority dan assumption tidak dimasukkan ke dalam tabel use-case narrative. Use case type dalam pembahasan semuanya termasuk ke dalam overview use case. Priority dibahas di tabel use-case ranking and priority matrix. Assumption tidak sertakan dalam pembahasan sebab dalam pembahasan menggunakan fakta atau keadaan yang sebenarnya yang ada di lapangan. Beberapa use case tidak memiliki semua komponen dan dikosongkan dalam tabel use-case narrative. Tabel 7.3. sampai dengan 7.19. merupakan use-casenarrative yang ada dalam siklus pengeluaran $\mathrm{CV}$ Makmur Abadi.

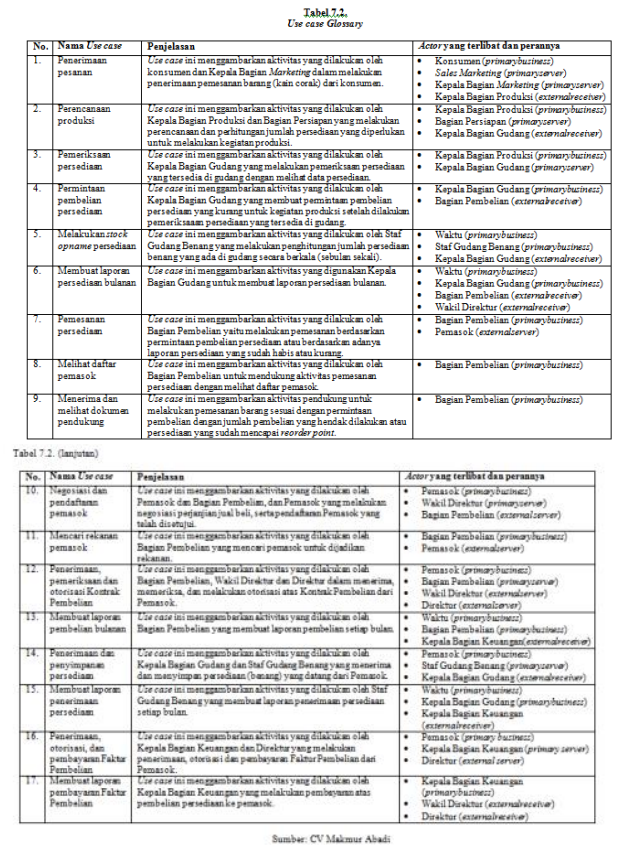

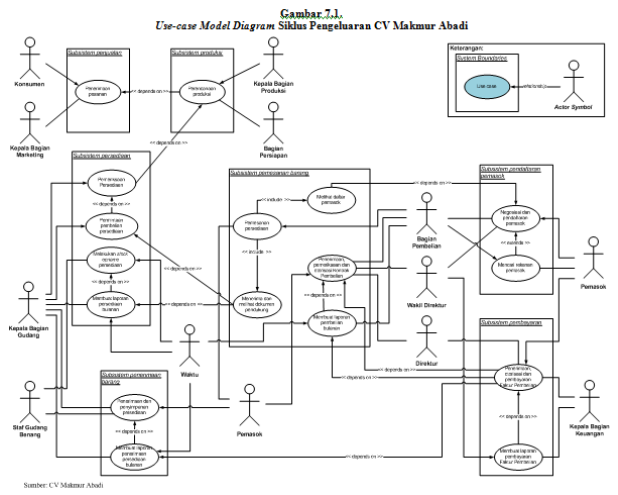
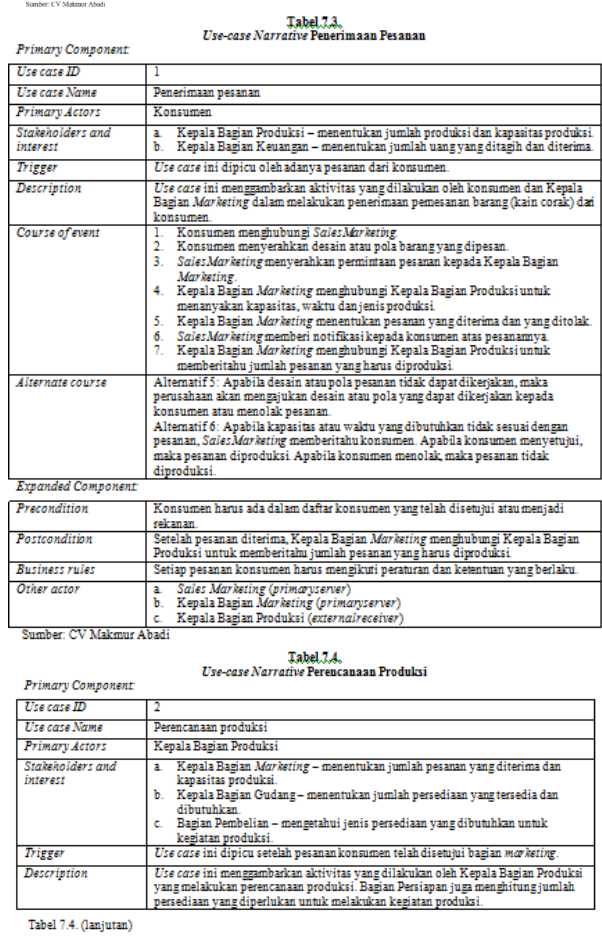

Primary Component

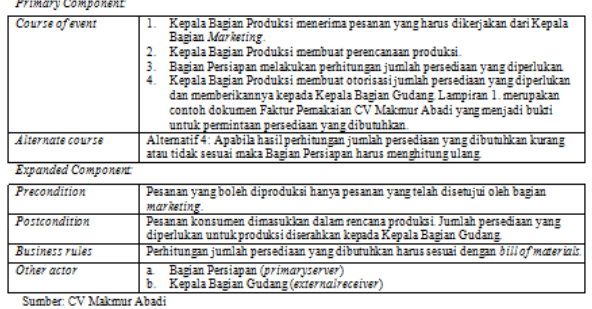


Jurnal Akuntansi Maranathaø Volume 10 Nomor 1, Mei 2018 : 1 - 16

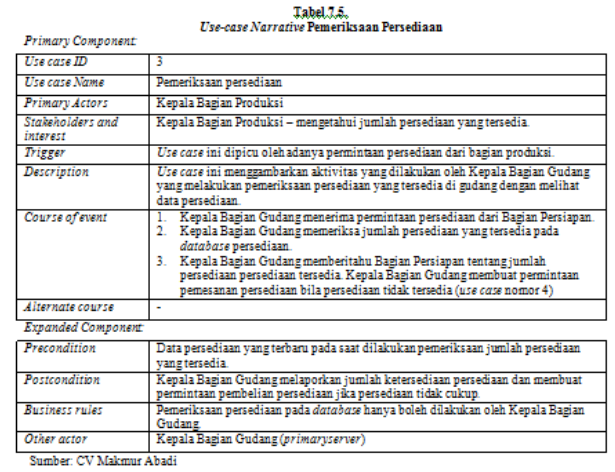

\begin{tabular}{|c|c|}
\hline Primary Component & $\begin{array}{l}\text { Iabel126.6. } \\
\text { Cse-case Narrative Permintaan Pembeliaan Persediaan }\end{array}$ \\
\hline Use case ID & 4 \\
\hline Use case Name & Perrmintaan pembelian perrediaan \\
\hline Primary.Actors & Kepala Bagin Gudang \\
\hline $\begin{array}{l}\text { Stakenholiders and } \\
\text { interest }\end{array}$ & Bagian Pembelian - menentukan junlah persediaan yang harus dipetan ke peraso ok \\
\hline Trigger & 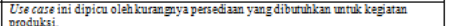 \\
\hline Description & 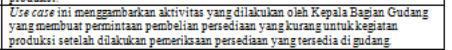 \\
\hline Course of event & 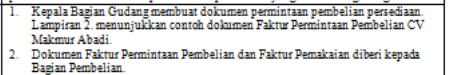 \\
\hline Aitemate course & \\
\hline \multicolumn{2}{|l|}{ Expanded Componert } \\
\hline Precondition & $\begin{array}{l}\text { Use case peneriksaan persediann sudah dilakukan dulu dengan hasil kurang gyya } \\
\text { persediann }\end{array}$ \\
\hline Postcondition & 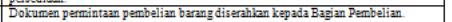 \\
\hline BuSiness TUies & $\begin{array}{l}\text { Permintaan pembelian persediaan harns dibuat dan disampaikan secara formal dan } \\
\text { tertulis (ada dokumennya) }\end{array}$ \\
\hline Other actor & a Bagian Penbelian (externairecefiter) \\
\hline \multicolumn{2}{|c|}{ Sumber: CV Maknur Abadi } \\
\hline Primary Component & $\begin{array}{l}\text { Tabel 2,2, } \\
\text { Use-case Narrative Melakulan Stock opname Persediaan }\end{array}$ \\
\hline Use case ID & 5 \\
\hline Use case Name & Melakukan stock opnome persedian \\
\hline Primaryictors & Walktu \\
\hline $\begin{array}{l}\text { Staitenoiders and } \\
\text { interest }\end{array}$ & $\begin{array}{l}\text { a. Kepala Bagian Gudang - mengetahui jumlah persedian yang ada di gudang } \\
\text { secara tepat. }\end{array}$ \\
\hline Trigger & $\begin{array}{l}\text { Use cases ini dipicu oleh ketentuan pensahaan yaitu setiap sebulan selali melakikikan } \\
\text { stock opname. }\end{array}$ \\
\hline Description & 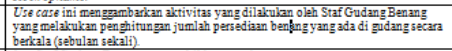 \\
\hline Course of event & 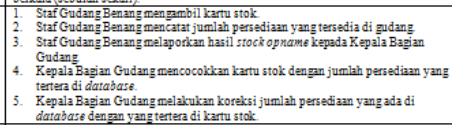 \\
\hline Aiternate course & 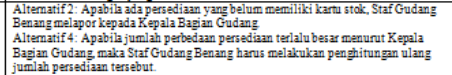 \\
\hline
\end{tabular}

Tabel 7.7. (anjutam)

Expanded Component

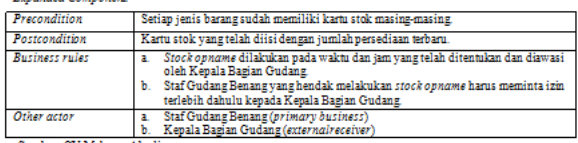

b. Star Gudang Benang (yrimary busthess)
Sumber CV Naknur Abadi

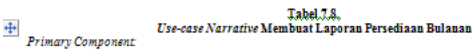

\begin{tabular}{|c|c|}
\hline Use case ID & 6 \\
\hline \begin{tabular}{|l|l} 
Use case Name \\
\end{tabular} & Membuat laporan persediaan bulanan \\
\hline Primaryictors & Waktu \\
\hline $\begin{array}{l}\text { Stakibhoiders and } \\
\text { interest }\end{array}$ & 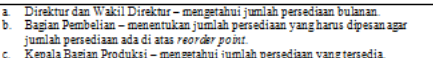 \\
\hline \begin{tabular}{|l|l|l} 
Trigger \\
\end{tabular} & $\begin{array}{l}\text { Usse cases ini dipicico olehketentuan persahahan yaitu setiap sebulan selalili membuat } \\
\text { laporan persedian bulanan }\end{array}$ \\
\hline Description & 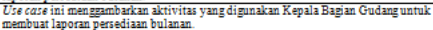 \\
\hline \begin{tabular}{|l} 
Course of ment \\
\end{tabular} & 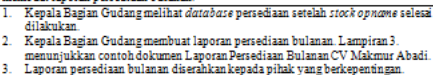 \\
\hline Aiterne & \\
\hline
\end{tabular}

onded Compone

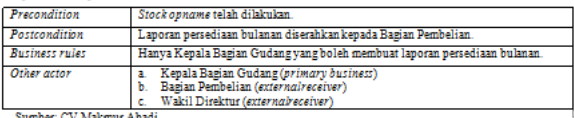

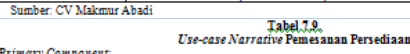

\begin{tabular}{|c|c|}
\hline mary $c_{0}$ & \\
\hline Use case ID & \\
\hline \begin{tabular}{|l} 
Use case Name \\
\end{tabular} & Penaranan Persediaan \\
\hline \begin{tabular}{|l} 
Primary Actors \\
\end{tabular} & Bagjan Pembelian \\
\hline $\begin{array}{l}\begin{array}{l}\text { Stabibihoiders and } \\
\text { interest }\end{array} \\
\end{array}$ & 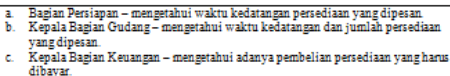 \\
\hline \begin{tabular}{|l|} 
Trigger \\
\end{tabular} & $\begin{array}{l}\text { Use case ini dipicu adanya permintaan pembelian persediaan dan atau melihat } \\
\text { laporan persedian bulanan }\end{array}$ \\
\hline \begin{tabular}{|l|} 
Description \\
\end{tabular} & 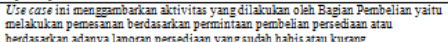 \\
\hline \begin{tabular}{|c|} 
Course of event \\
\end{tabular} & 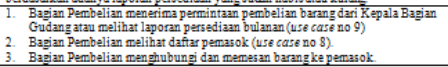 \\
\hline \begin{tabular}{|l|l} 
Alternate course \\
\end{tabular} & 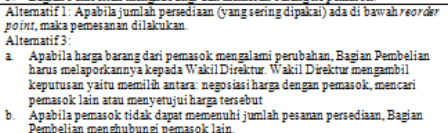 \\
\hline
\end{tabular}

\begin{tabular}{|l|l|}
\hline Precondition & Sudah ada daftar pemasok yang mencukupi kebuttuhan persedian (berbagai macam \\
\hline
\end{tabular}

\begin{tabular}{|c|c|}
\hline Precondition & $\begin{array}{l}\text { Sudah ada daftar perassok yang mencukupi kebutuhan persedian (berbagai macam } \\
\text { jenis benangy). }\end{array}$ \\
\hline \begin{tabular}{|l|l|l} 
Postcondition \\
\end{tabular} & Pemesanan barang ge pemas ok behassil dilakukan. \\
\hline \begin{tabular}{|l} 
Business ruies \\
\end{tabular} & 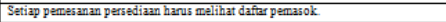 \\
\hline Other actor & Pemasol (externaisenter) \\
\hline
\end{tabular}

Sumber CV Nakmur Abadi

\begin{tabular}{|c|c|}
\hline Primary Component: & $\begin{array}{l}\text { Tabel } 1010,0 \text {, } \\
\text { ative Melibat Daftar Pemasolk }\end{array}$ \\
\hline Use case ID & 8 \\
\hline Use case Name & Melihat daftar pemasok \\
\hline Primary.Actors & Bagjan Pembelian \\
\hline $\begin{array}{l}\text { Staikhoididers and } \\
\text { interest }\end{array}$ & $\begin{array}{l}\text { a Wakil Direktur - mengetahui data penas ok yang menjadi reklanan. } \\
\text { b. pemasolk - mengetrahui adanya pembeli yang berpotensi. }\end{array}$ \\
\hline $\begin{array}{lll}\text { Trigger } \\
\end{array}$ & Use case ini dipicu dari 15 cases pemes anan persedian. \\
\hline Description & 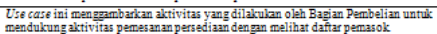 \\
\hline Course of event & 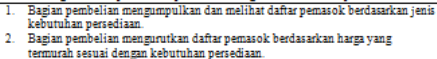 \\
\hline Aitarnate & 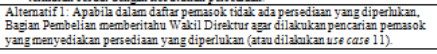 \\
\hline
\end{tabular}


Jurnal Akuntansi Maranathan Volume 10 No. 1, Mei 2018 : 1 - 16

Tabel 7.10. (lanjutan)

Expanded Component

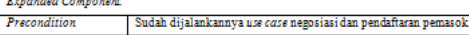

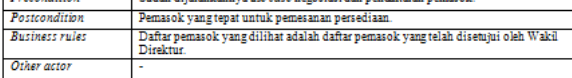

Sumber CV Nakruur Abad

Iabel 2.1.1,
Use-case Narrative Menerima dau Nelihat Dolumen Pendukung

\begin{tabular}{|c|c|}
\hline \multicolumn{2}{|l|}{ Primary Component } \\
\hline Use case ID & 9 \\
\hline Use case Name & Menerima dan melihat dokumen pendukmg \\
\hline \begin{tabular}{|l|l} 
Primary Actors \\
\end{tabular} & Bagian Pembelian \\
\hline 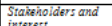 & Kepala Bagian Gudang - mangetahui permintaan pembelian persediaan diterima atau \\
\hline 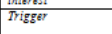 & 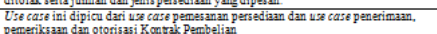 \\
\hline Description & 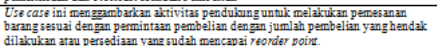 \\
\hline Course of event & 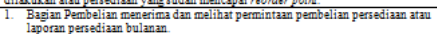 \\
\hline Aiternate coulys & ( \\
\hline \multicolumn{2}{|c|}{ Expanded Component } \\
\hline Precondition & 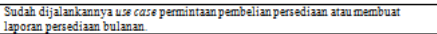 \\
\hline Postcondition & 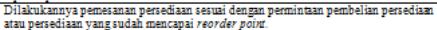 \\
\hline \begin{tabular}{|l|l|l} 
Business ruies \\
\end{tabular} & Dokumen yang diterima dan dilhat hanya dokumen fermi pents ahann \\
\hline Other actor & \\
\hline
\end{tabular}

Sumber: CV Maknur Abadi

\begin{tabular}{|c|c|}
\hline Primary Component: & $\begin{array}{l}\text { Tabel l.12, } \\
\text { Cse-case Narrative Negosiasi dau Pendaftaran Pemasolk }\end{array}$ \\
\hline Use case ID & 10 \\
\hline Use case Name & Negososisasi dan pendaftaran pemasol. \\
\hline \begin{tabular}{|l} 
Primary Actors \\
\end{tabular} & Pemasok \\
\hline $\begin{array}{l}\text { Stakibhoiders and } \\
\text { interest }\end{array}$ & 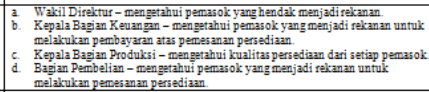 \\
\hline \begin{tabular}{|l|l|} 
Trigger \\
\end{tabular} & 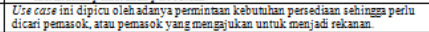 \\
\hline \begin{tabular}{|l|l|} 
Description \\
\end{tabular} & 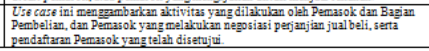 \\
\hline
\end{tabular}

Tabel 7.12 (anjutran)

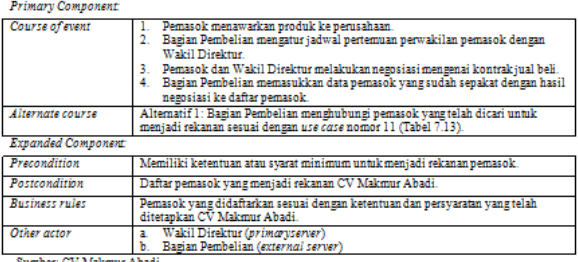

Tabel 2.13

\begin{tabular}{|c|c|}
\hline Primary Component & Use-case Narrativi \\
\hline Use case ID & 11 \\
\hline \begin{tabular}{|l|l|l} 
Use case Name \\
\end{tabular} & \begin{tabular}{|l|l|} 
Mencari rekanan pemasolk \\
\end{tabular} \\
\hline \begin{tabular}{|l} 
Primary Actors \\
\end{tabular} & Bagjan Pembelian \\
\hline \begin{tabular}{|l|l|l|l} 
Staishoiders and \\
intarest
\end{tabular} & Wakil Direktur - mengetahui penass ok yang hendakk menjadi fekkan an \\
\hline Trigger & $\begin{array}{l}\text { Use case ini dipicu oleh permintaan manajemen untulk mencari pemasok untulk } \\
\text { memenuhi kebutuhan persediann }\end{array}$ \\
\hline \begin{tabular}{|l|l|l} 
Description \\
\end{tabular} & 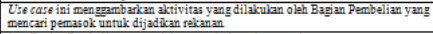 \\
\hline \begin{tabular}{|c|} 
Course of ewent \\
\end{tabular} & 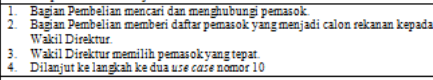 \\
\hline \begin{tabular}{|l|l} 
Aitemate course \\
\end{tabular} & \\
\hline \multicolumn{2}{|l|}{ Expanded Component } \\
\hline Precondition & 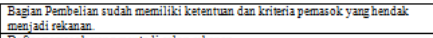 \\
\hline \begin{tabular}{|l|l|} 
Postcondition \\
\end{tabular} & \begin{tabular}{|l|l} 
Daffirs pemasol yang menj $\mathrm{adi}$ calo \\
\end{tabular} \\
\hline \begin{tabular}{|l|l} 
Business ruies \\
\end{tabular} & $\begin{array}{l}\text { Pemasol yang hendakk menjadi reklanan harus menenuhi ketentuan dan kriteria yang } \\
\text { telah dittetagkan. }\end{array}$ \\
\hline ther & \\
\hline
\end{tabular}

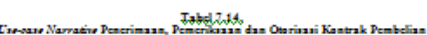

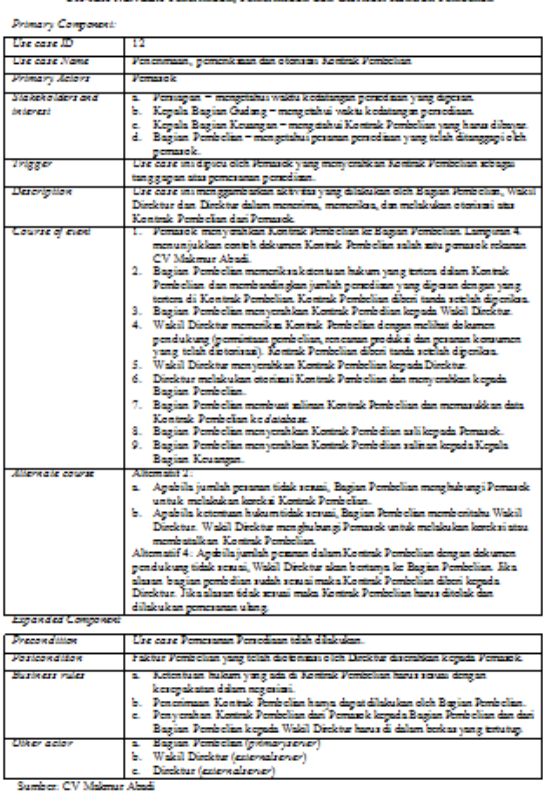

Tabel:15.5.
Use-cese Narrative Membuat Laporan Pembelian Bulanan

\begin{tabular}{|c|c|}
\hline & \\
\hline Use case ID & 13 \\
\hline Use case Name & Membuat laporan pembelian bulanan \\
\hline \begin{tabular}{|l|l} 
Primaryidctors \\
\end{tabular} & Waktu \\
\hline \begin{tabular}{|l|}
$\begin{array}{l}\text { Staibhoiders and } \\
\text { interest }\end{array}$ \\
\end{tabular} & 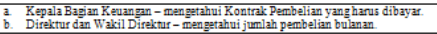 \\
\hline \begin{tabular}{|l|l|l|l} 
Thergest \\
Trger
\end{tabular} & 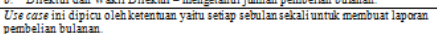 \\
\hline Description & 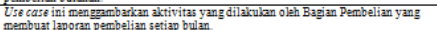 \\
\hline \begin{tabular}{|c|c|c|c|} 
Coutse of event \\
\end{tabular} & 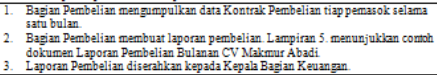 \\
\hline \begin{tabular}{|l|} 
Aiternate course \\
\end{tabular} & 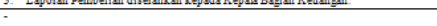 \\
\hline Expanded Component, & \\
\hline Precondition & Adanya pembelian persediaan ke penaso ok: \\
\hline \begin{tabular}{|l|} 
Postcondition \\
\end{tabular} & Laporan pembelian bulanan y yng diserahkan kepada Keppla Bagian Kevangan \\
\hline \begin{tabular}{|l} 
Bustiness ruies \\
\end{tabular} & \\
\hline Other actor & 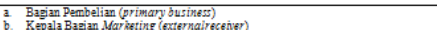 \\
\hline
\end{tabular}

\begin{tabular}{|c|c|}
\hline Primary Component & $\begin{array}{l}\text { Tabet } 7.16, \\
\text { Use-case Narrative Penerimaan dan Peuyimpanan Persediaan }\end{array}$ \\
\hline Use case ID & 14 \\
\hline \begin{tabular}{|l|l} 
Use case Name \\
\end{tabular} & Penerimaan dan penyimpanan persediaan \\
\hline PrimaryActors & Pemasok \\
\hline 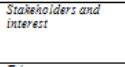 & 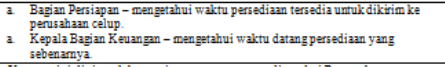 \\
\hline Trigger & Use case ini dipicu oleh penerimaan pesanan persedian dari Pemasolk \\
\hline Description & 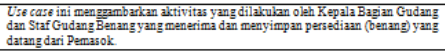 \\
\hline \begin{tabular}{|c|c|c|c|c|} 
Coure of elent \\
\end{tabular} & 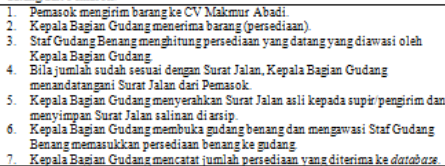 \\
\hline
\end{tabular}


Jurnal Akuntansi Maranathaø Volume 10 Nomor 1, Mei 2018 : 1 - 16

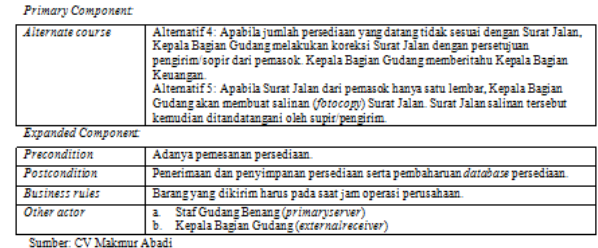

Sumber: CV Nakrmur Abadi

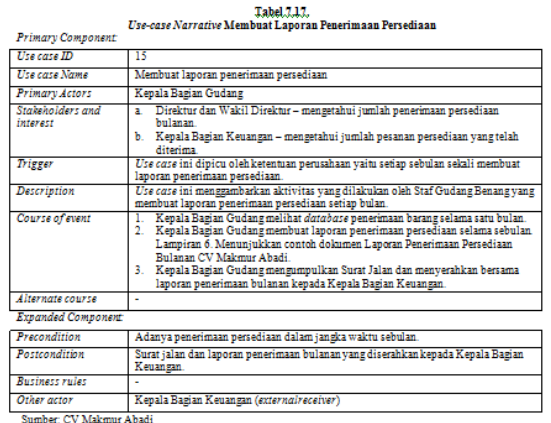

Sumber: CV Makmus Abadi

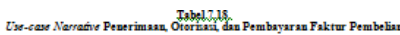

\begin{tabular}{|c|c|}
\hline \\
\hline Lat tate ID & 16 \\
\hline 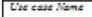 & 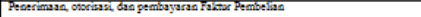 \\
\hline Primsy Astorn & Pemasos: \\
\hline 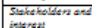 & 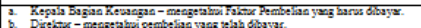 \\
\hline Thisiger & 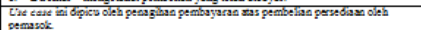 \\
\hline 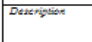 & 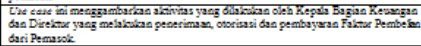 \\
\hline 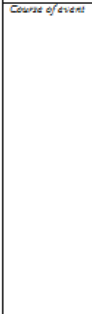 & 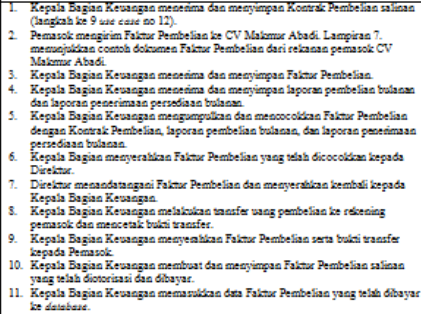 \\
\hline 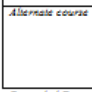 & 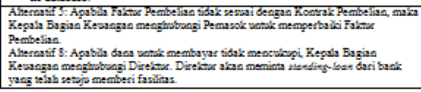 \\
\hline \multicolumn{2}{|c|}{ Expested Componstet } \\
\hline 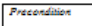 & 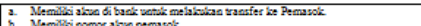 \\
\hline 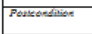 & 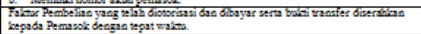 \\
\hline 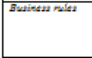 & 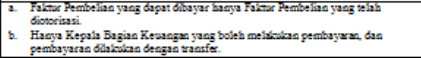 \\
\hline Olles actor & 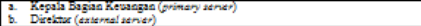 \\
\hline
\end{tabular}

Tabel. 7.19
Use-case Nerrative Membuat Laporan Pembayaran Faltur Pembelian

\begin{tabular}{|c|c|}
\hline \multicolumn{2}{|c|}{ Primary Component } \\
\hline Use case ID & 17 \\
\hline Use case Name & Membuat laporan pembayaran Falktur Pembelian \\
\hline PrimaryActors & Kepala Bagjian Keuangan \\
\hline $\begin{array}{l}\text { Srakibhoiders and } \\
\text { interest }\end{array}$ & $\begin{array}{l}\text { Direktur dan W'akil Direktur - mengetahui pengeluaran bulanan atas pembelian } \\
\text { persedian }\end{array}$ \\
\hline Trigger & 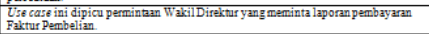 \\
\hline Description & 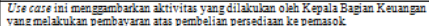 \\
\hline Course of elent & 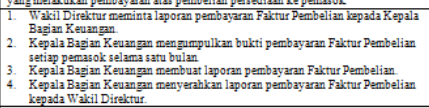 \\
\hline Altemate course & . \\
\hline \multicolumn{2}{|c|}{ Expanded Component } \\
\hline Precondition & Use case penerimain, otorisasi, dan pembayaran Falktur Pembelian sudah dijalankan \\
\hline Postcondifition & 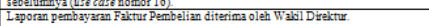 \\
\hline Business ruies & \\
\hline Other actor & 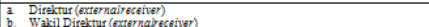 \\
\hline
\end{tabular}

